\title{
Nursing students' experiences of bullying in clinical practice
}

\author{
Florence L. Luhanga*1, Vivian A. Puplampu ${ }^{1}$, Sherry Arvidson ${ }^{1}$, Adeyemi Ogunade ${ }^{2}$ \\ ${ }^{1}$ Faculty of Nursing, University of Regina, USA \\ ${ }^{2}$ Faculty of Education, University of Regina, USA
}

Received: August 1, 2019

DOI: $10.5430 /$ jnep.v10n3p89
Accepted: November 24, 2019 Online Published: December 10, 2019

URL: https://doi.org/10.5430/jnep.v10n3p89

\begin{abstract}
Bullying is a major concern in the nursing profession because of its implications for patients' safety, the health of nurses and nursing students, as well as on the workforce in the healthcare system. The purpose of the study was to explain the incidence and state of bullying experienced by nursing students in the undergraduate nursing program during clinical practice. Fifty-five undergraduate nursing students participated in the mixed methods research conducted in a tertiary institution in Western Canada. Participants completed an online survey and an individual interview. Survey data were analyzed using descriptive statistics while thematic analysis was employed for the open-ended questions on the survey and individual interviews. The findings from the study showed that a small number of students four $(7.7 \%)$ frequently experienced bullying in the clinical setting with clinical instructors and practicing nurses being the main perpetrators. Students reported anxiety connected with going for clinical practice however a unique finding from this study was that the affected students continued to go for clinical practice and decided to remain in the program because of their goal to become registered nurses. Peers from the program were one of the key support systems for the students when they experienced the negative behavior. Irrespective of the low incidence of bullying at the research site, the impact of the behavior aligns with the literature. The findings from this study has the potential to inform clinical practices and policies in undergraduate nursing programs.
\end{abstract}

Key Words: Nursing students, Bullying, Clinical setting, Clinical practice, Mixed methods research

\section{INTRODUCTION}

Bullying of nursing students in the clinical setting has become a major focus in nursing education and a global concern in the literature. ${ }^{[1-3]}$ Some scholars assert that nursing students have the highest risk of experiencing bullying in the workplace because they are often younger, they have less clinical and life experience, fewer coping skills, and they have minimal power in the work environment's hierarchy. ${ }^{[1,2,4,5]}$ In this paper, bullying is defined as a repeated or a single negative behavior involving vertical or horizontal violence. ${ }^{[6-8]}$ Vertical violence is a negative behavior that occurs where there is a power imbalance between the victim and the perpetrator, through which the victim feels inferior such as between clinical instructors and students. ${ }^{[6,8]}$ Horizontal violence on the other hand involves negative behaviours among individuals with equal power such as among students. ${ }^{[6]}$ Examples of bullying behaviours described in the literature include withholding information, ignoring, gossiping, humiliating, undervaluing, judging, denying learning opportunities, and intimidating the victim..$^{[2,3,6-9]}$ The failure to address bullying in nursing programs during students' clinical practice can potentially lead to a culture of tolerance

*Correspondence: Florence L. Luhanga; Email: Florence.luhanga@uregina.ca; Address: Faculty of Nursing, University of Regina, USA. 
towards this unprofessional conduct.

Baltimore (2006) ${ }^{[10]}$ proposed that the root cause of bullying in nursing starts in the academic setting, where some nurse educators abuse their power and flourish through feelings of superiority by controlling students and more junior staff members. Several scholars concur that bullying begins during undergraduate nursing education and continues to thrive in nursing practice. ${ }^{[6,9,11-14]}$ Undergraduate nursing students are expected to complete a minimum amount of clinical practice hours as part of their undergraduate nursing program. For example, in Australia, nursing students must undertake a minimum of 800 clinical placement hours in their undergraduate nursing program. ${ }^{[15]}$ Undergraduate nursing programs in Canada have different requirements for clinical hours however, the Canadian Higher Education Database $(2012)^{[16]}$ recorded that nursing students spend approximately 1,700 hours in the clinical settings to gain nursing skills and knowledge needed to become competent practitioners. Clarke, Kane, Rajacich, and Lafreniere (2012) revealed that $88.72 \%$ of nursing students in Canada experienced bullying behaviours in the clinical setting. Similarly, Borrott, Day, Sedwick, and Levett-Jones (2016) ${ }^{[17]}$ concurred that nursing students experienced or witnessed bullying behaviors during clinical practice. Clarke, Kane, Rajacich, and Lafreniere (2012) found that clinical instructors were reported as the largest source of bullying at $30 \%$, followed by classmates at $15 \%$ and patients and their families at $14 \%$. Evidence in the literature suggested many nursing students underreport instances of bullying behaviours, and thus, the number of incidents could be much higher. ${ }^{[2,9]}$ Possible reasons for underreporting include the perception that tolerating bullying behaviours is part of the job, the fear of being victimized, worrying about the negative consequences, and the perceived lack of support from the educational program. ${ }^{[2,6,18]}$ The negative impact of bullying on nursing students includes overall increased in physical and psychological morbidities such as increased stress, reduced self-esteem and confidence, poor concentration, anxiety, sleep disturbances, gastrointestinal problems, depression, and inability to effectively learn. ${ }^{[1,3,4,19,20]}$ Additionally, bullying behaviours may affect the quality of nursing care that students provide and influence their intention to leave the profession. ${ }^{[3,4]}$

Although bullying of nursing students is a serious problem that needs to be addressed, no studies could be found that have explored bullying among nursing students in the Canadian province where the study was conducted. As educators, it is imperative that we understand the phenomenon of bullying, as it influences negatively on students' learning and wellness, patients' safety, workforce in the health care, and it is also unprofessional to our stated intent as instructors in a caring profession. The purpose of the research was to explain the nature of bullying in the undergraduate nursing program during students' clinical practice. Ultimately, the research team sought to establish a clear picture of the problem in order to identify recommendations to improve future clinical placement experiences for nursing students.

\subsection{Research questions}

The research questions that guided the study were: 1) Do nursing students experience bullying during clinical practice? 2) What is the nature of bullying experienced by nursing students during clinical practice? 3) What are the impacts of bullying on nursing students?

\section{Methodology}

Due to the complexity of the phenomenon of bullying, the researchers used a concurrent mixed methods approach to guide the study. According to Creswell (2014), ${ }^{[21]}$ a mixed methods approach is beneficial when either the quantitative or qualitative approach by itself is inadequate to get a better insight or understanding of the research problem. Data were collected through an online survey and individual interviews, to gather qualitative data to get a better understanding of the nature of bullying in the undergraduate nursing program during clinical practice. The concurrent mixed method approach allowed the researchers to collect quantitative and qualitative data at the same time, analyze the data, and combine the findings to enable integration of data as well as interpretation and reporting of the findings. ${ }^{[22]}$

\subsection{Setting and sample}

The target population for this study included all students enrolled in a four-year collaborative undergraduate nursing program between one university and a Polytechnic School of Nursing in Western Canada. The program is offered in three locations within the province with a current total population of 1200 nursing students (D. Gregory, personal communication, November 13, 2019). Students enrolled in the undergraduate nursing program begin practice education in the first semester of year one and start their clinical practicum in the first year during the second semester. Students are expected to complete 1,452 hours of clinical experience in the four-year program. ${ }^{[23]}$

The study was conducted in two of the three locations where the program is offered and the researchers reside. The main inclusion criteria for all phases of the study were: being enrolled in the program either part-time or full time; and having experienced bullying in the clinical setting. Of the 55 undergraduate students who took part in the study, 49 students were involved in the quantitative phase while six 
volunteered to be interviewed after participating in the survey. The response rate to the questionnaires was $4 \%$. These six participants who were interviewed were all female and included three second-year, one third-year, and two fourth-year students.

\subsection{Ethical considerations and recruitment}

Ethical approval for the study was obtained from the participating educational institution's research ethics review board (REB File \# 2017-072) prior to recruitment and data collection. In addition, permission was obtained from the associate deans to access the students. Following ethical approval, an email was sent to students through the program's student portal inviting all nursing students to participate in the research study. Students who consented to participate in the study were provided with information on how to access the Qualtrics online survey and the process for voluntary participation in the individual interview. The students were informed that participation was voluntary, responses were anonymous, and they could withdraw from the study at any time. The students' completion of the online survey implied consent. For the interview, participants' written and verbal consents were obtained prior to the interview process. To ensure anonymity and confidentiality, participants' names and any identifying information were removed from transcripts and replaced by numbers. Only members of the research team had access to the data. Following the university policy, all data are stored in a locked cabinet in the principal investigator's office.

\subsection{Data collection and analysis}

\subsubsection{Quantitative data}

An online survey using Qualtrics software was used for data collection. The survey took 20-30 minutes to complete.

The survey tool had three sections: demographics, 53 multiple-choice questions, and two open-ended questions developed from a literature review on nursing students' experiences of bullying during clinical practice. The questions covered topics such as students' experience with bullying, students' responses to bullying, reasons why students did not report the behavior, the impact of bullying, coping strategies used for coping with bullying, and knowledge of formal policies/procedures on bullying in their institution. Before posting the survey online, a pilot test was performed by a nonresearch member to assess overall structure and readability of the online tool.

Statistical Package for the Social Sciences (SPSS) version 23 was used to conduct descriptive statistical analysis of the survey data due to the small sample size. The research team composed of the four authors and one research assistant col- laboratively read through the two open-ended questions to identify the themes across the data.

\subsubsection{Qualitative data collection and analysis}

Six participants volunteered to take part in an individual interview. A semi-structured interview guide covered topics such as the meaning of bullying, the types and sources of bullying experienced during clinical practice, coping strategies, the impact of bullying behaviour on students, and the reporting practices of students. The individual interview lasted between 30 and 60 minutes. To avoid conflict of interest, a graduate research assistant interviewed the participants. Interviews were audiotaped and transcribed verbatim. The research team used thematic analysis to identify patterns from the data on the topic. ${ }^{[24,25]}$

\subsection{Rigour}

To ensure the rigour of the research process, a number of trustworthy strategies were used, including two sources of data collection, peer review and debriefing, the use of direct quotations, analytical decisions, and an audit trail. ${ }^{[26]}$ The researchers used reflective practices to ensure their personal biases such as knowledge of the literature on the topic were acknowledged and did not influence the data collection and analysis. ${ }^{[27]}$ Furthermore, the researchers met frequently to discuss their findings from the data during data analysis to arrive at consensus on the topic.

\section{FINDINGS}

\subsection{Findings from quantitative data}

Forty-nine students took part in the quantitative phase of the study. Most of the participants were female, 43(82.7\%). The highest age range was between 18-24 years, 37(71.2\%). The majority of the participants were second-year students, $26(50 \%)$. The largest racial groups were Caucasian, 34(65\%) followed by Black/African/Caribbean descent, $8(15.4 \%)$ (see Table 1).

Regarding incidence of bullying in the clinical setting, 4 (7.7\%) students reported bullying had occurred "frequently" and 33 (64\%) students reported bullying occurred "occasionally". The highest incidence of bullying was reported among second-year students (see Table 2). The two main types of bullying were verbal bullying and social exclusion (see Table 2). Clinical instructors, were the highest reported sources of bullying, 25 (48.1\%) followed by registered nurses, 17 (32\%), and licensed practical nurses, 14 (26.9\%) (see Table $3)$.

The main effects of bullying on the students were: increased stress levels, gastrointestinal disturbances, fatigue, sleep disturbances, anxiety, loss of concentration, and reduced morale 
and motivation. The highest sources of support for students when they experienced bullying behaviour were their friends $20(38.5 \%$ ) (see Table 3). Many of the students 23 (44\%) did not know if the nursing program had a formal procedure for reporting bullying in the clinical setting.

\subsection{Findings from qualitative data}

The researchers identified five themes emerging from the data: the meaning of bullying, factors contributing to bullying, the impact of bulling, coping with bulling, and preventing bullying.

\subsubsection{Theme 1: The meaning of bullying}

The categories under this theme are "definition of bullying," "the setting and sources of bullying," and "forms and incidence of bullying." Most participants defined bullying as an action or behaviour that is interpreted as mean and aimed at devaluing or putting someone down, creating a negative environment in which to learn and work. A second-year student described bullying as the following:

Trying to intimidate somebody especially when you are in a position where you have more power or you are a little more advanced than the other person, then you try to take advantage of that by making someone feel uncomfortable in an environment by picking on them.

Table 1. Demographic data of nursing students who completed the survey

\begin{tabular}{|c|c|c|c|}
\hline \multicolumn{2}{|c|}{ Demographic Data } & \multirow{2}{*}{$\begin{array}{l}\text { Frequency } \\
6\end{array}$} & \multirow{2}{*}{$\begin{array}{l}\text { Percent } \\
11.5\end{array}$} \\
\hline Conder & Male & & \\
\hline Genues & Female & 43 & 82.7 \\
\hline \multirow{4}{*}{ Age } & 18-24 years & 37 & 71.2 \\
\hline & 25-34 years & 9 & 17.3 \\
\hline & 35-44 years & 1 & 1.9 \\
\hline & 45 and older & 1 & 1.9 \\
\hline \multirow{4}{*}{$\begin{array}{l}\text { Year of } \\
\text { study }\end{array}$} & First & 4 & 7.7 \\
\hline & Second & 26 & 50.0 \\
\hline & Third & 12 & 23.1 \\
\hline & Fourth & 7 & 13.5 \\
\hline \multirow{7}{*}{$\begin{array}{l}\text { Ethnic } \\
\text { background }\end{array}$} & Indigenous & 2 & 3.8 \\
\hline & Black/African/Caribbean & 8 & 15.4 \\
\hline & Caucasian & 34 & 65.4 \\
\hline & East Asian/Chinese/Japanese & 2 & 3.8 \\
\hline & South Asian/Indian/Pakistan & 1 & 1.9 \\
\hline & Filipino/Asian & 1 & 1.9 \\
\hline & East Asian Caucasian & 1 & 1.9 \\
\hline \multirow{3}{*}{$\begin{array}{l}\text { Residency } \\
\text { status }\end{array}$} & Canadian citizen & 43 & 82.7 \\
\hline & Permanent resident & 4 & 7.7 \\
\hline & International student & 2 & 3.8 \\
\hline
\end{tabular}

Table 2. Experiences and types of bullying

\begin{tabular}{|c|c|c|c|c|c|c|}
\hline \multirow{2}{*}{ Item } & \multicolumn{6}{|c|}{ Frequency of experiencing bullying behaviour } \\
\hline & No response & Never & Occasionally & Frequently & Always & Total \\
\hline \multicolumn{7}{|l|}{ Year of Study } \\
\hline First & 1 & 1 & 2 & 0 & 0 & 4 \\
\hline Second & 7 & 0 & 15 & 4 & 0 & 26 \\
\hline Third & 1 & 1 & 10 & 0 & 0 & 12 \\
\hline Fourth & 1 & 0 & 6 & 0 & 0 & 7 \\
\hline \multicolumn{7}{|l|}{ Types of Bullying Behaviours } \\
\hline I was placed under undue pressure to produce work & 0 & 8 & 15 & 13 & 1 & 37 \\
\hline My clinical assignment/task was excessively scrutinized & 0 & 10 & 13 & 11 & 3 & 37 \\
\hline Being unfairly or unjustly criticized & 0 & 8 & 18 & 10 & 2 & 38 \\
\hline Being threatened with a poor evaluation & 0 & 10 & 18 & 9 & 1 & 38 \\
\hline I have experienced non-verbal innuendos & 0 & 5 & 20 & 9 & 3 & 38 \\
\hline My efforts were undervalued & 0 & 8 & 17 & 9 & 3 & 37 \\
\hline Impossible expectations were set for me & 0 & 9 & 20 & 8 & 1 & 38 \\
\hline I experienced destructive criticism & 0 & 6 & 22 & 7 & 2 & 37 \\
\hline I was harshly judged & 0 & 11 & 19 & 7 & 0 & 37 \\
\hline I was belittled or humiliated in front of others & 0 & 11 & 19 & 6 & 1 & 37 \\
\hline I was ignored or excluded & 0 & 14 & 14 & 4 & 4 & 36 \\
\hline
\end{tabular}

Some participants thought that one could experience a be- know the clinical or technical definition is repetitive but I haviour once and know it is bullying and that it does not don't really think it has to be repetitive to be called bullying." have to occur repeatedly. A third-year student explained "I Analysis of the data revealed that the incidence of bully- 
ing during clinical practice is higher than what is reported. For instance, when asked whether she had experienced bullying, a second-year student, stated, "personally I had not experienced bullying in clinical practice." However, while describing the relationship between nursing students and nurses on the units, the student declared:

... some nurses don't even care about what you are doing and when they know you are a student they just ignore you. . . I have been in a situation whereby I couldn't tell the nurse what was happening because she would always just ignore me. . . (Third year student)

Table 3. Sources of bullying and persons nursing students approached to report bullying behavior

\begin{tabular}{lll}
\hline \multirow{2}{*}{ Item } & \multicolumn{2}{c}{ Frequency of Behaviour } \\
\cline { 2 - 3 } & Frequency & Percentage \\
\hline Sources of Bullying & 25 & 48.1 \\
Clinical Instructor & 17 & 32.7 \\
Registered nurse & 14 & 26.9 \\
Licensed practical nurse & 10 & 19.2 \\
Classmate or other nursing students & 10 & 19.2 \\
Patient & 4 & 7.7 \\
Patient's family member or friends & 4 & 7.7 \\
Nursing aide & 3 & 5.8 \\
Physician & 2 & 3.8 \\
Other healthcare practitioner & 14 & 26.9 \\
Persons students approached to report behaviour & \\
Classmate & 6 & 11.5 \\
Clinical instructor & 20 & 38.5 \\
Friend & 15 & 28.8 \\
Parents & 10 & 19.2 \\
No one & 4 & 7.7 \\
Nursing Program Advisor & 1 & 1.9 \\
Someone reported it for me & 1 & 1.9 \\
Nursing instructor I trust & 1 & 1.9 \\
Site coordinator & &
\end{tabular}

Participants shared that bullying occurs mostly in the clinical setting and that nurses are the main sources of bullying. A fourth-year student said:

I would say nurses. Nurses can be really harsh when we are in clinical and they are under a lot of pressure and so having students come in can be a good thing for them but it can also be more stressful for them as well.

The main forms of bullying the students had experienced were, namely verbal bullying and social exclusion. For example, a fourth-year student noted "when you are working

Published by Sciedu Press with a patient maybe given them an injection or giving some medication and there would be some negative comments made in front of my patient by the nurse to make me look bad..." None of the six participants in the qualitative study had been physically harassed or had heard about physical bullying of their peers during clinical practice.

\subsubsection{Theme 2: Factors contributing to bullying}

Participants identified the following major factors that work together to contribute to bullying in the clinical setting: stress, inconsistency in communication, and cultural safety. Stress comes from the demanding work environment in the hospital. A fourth-year student shared "my preceptor right now is working so much overtime and I understand that overtime pays well but guess what you are way less able to deal with stress when you are working that number of hours". Another major factor contributing to bullying in the clinical environment that emerged from the data was inconsistency in communication between clinical instructors and nurses on the unit. A third-year student described this inconsistency in communication as follows: "So I feel like there is lack of communication or at least in this particular instance it was caused by a lack of communication between the wards expectation for students and the instructor ..." The students echoed that communication between clinical instructors and nurses needs to be clear and smooth in order to enhance their experience in the clinical setting. Cultural safety that is how a group is perceived and treated ${ }^{[28]}$ was identified as another contributing factor to bullying in the clinical setting. A small number of students from the study, four, who participated in the interview identified themselves as Blacks and attributed part of the negative behavior they experienced to their racial background. A second year Black student expressed “. . . I am usually the only black girl in the class ... and I try to be friends with them [classmates] but they are not really interested". Another second year student shared "honestly, I will just say because I am a black lady I have definitely grown a thick skin and little things don't bother me anymore."

\subsubsection{Theme 3: Impact of bullying}

Many of the participants expressed that they were scared of going to their clinical practice after being bullied. A fourthyear student shared their experience: "I was very nervous to go to clinical and I didn't feel I could handle the workload. Yeah I just felt like it was either a test from the instructor to see if I can handle it." Some participants were afraid they would not be able to graduate on time, as some students had experienced. Another fourth-year student highlighted:

With my clinical instructor, I kind of took it personally and it was also because it was my fourth year so I was really worried that it was going 
to impact my graduation and so there was a lot on the line and I probably could have handled it a little bit better. It ended up being okay in the end but it was hard to maintain . . .

Participants shared that experiencing bullying reduced their confidence and self-esteem. "When you are being bullied and when you are kind of being purposefully shot down . . . So it like it really messes with your self-confidence". All the participants were scared to go for their clinical practice and worried that they would not graduate as scheduled because of the bullying behaviour.

\subsubsection{Theme 4: Coping with bullying}

The main categories under coping with bullying are "preparing for clinical practice", "desiring to be a nurse", and "finding support systems". The students said they studied very hard when preparing for clinical so that they could master the content and skills. A fourth-year student shared "I just kept working on things, studying hard and trying to get a good sleep and starting up the next day". All the students discussed that one of the methods of coping with bullying was considering their long-term goal of becoming a nurse. A fourth-year student shared "many times I wanted to quit because of the incidence and discouragement from instructors but yeah it was the love of the profession that kept me in it." In addition to the students' passion for nursing, they commented that having a support system was a very strong coping strategy. The students' main support system was their friends. A third-year student expressed, "If you have to step off the floor to have a teary moment then you have to step off the floor and it is just a little bit nicer for some people if they have a friend to give them a hug at the same time." Although not all the participants experienced bullying during clinical practice, they all concurred that preparing for clinical, talking to someone, and taking care of oneself were strong copying mechanisms to address bullying during clinical practice.

\subsubsection{Theme 5: Preventing bullying behaviours}

Participants provided many suggestions on preventing bullying in the clinical setting including training, creating a comfortable learning environment, promoting effective communication, and advocating for students. A second-year student shared that training for floor nurses could be "just a quick seminar, even in the morning so that they can have a good outlook towards being with students in the workplace and so[that] they don't just think being with students and teaching students are trouble for them." In addition to the suggestion of receiving more training, the students shared that the environment must be comfortable for learning. A third-year student said "I think like for students I feel it is really important to remember that we are students and [we] are learning. . . If we are going to make a mistake charting, we might as well make it in our first year. . ." Students would like to see that the units are given clear and consistent communication on the expectations of students during clinical practice. A fourth-year student said, "I would suggest more consistency between clinical instructors. Their expectations [should] be more similar and the instructors should be more patience with the students I suppose." Furthermore, the students would like to have a mediator from the faculty to step in instead of requiring the students to go back to the perpetrators. A fourth-year student shared:

Because when it is just a student and an instructor bullying the student and you are trying to have a discussion with them, well it is their word over yours. So you don't really feel supported. I felt like I should have a third party there just in case ... right now there is no protocol or safe place.

The data from the interviews support and elaborate on the survey data that bullying occurs in the nursing program although the frequency of the behaviour is small. A summary of the themes that emerged from the interview data and the categories under each theme is provided in Table 4.

Table 4. Summary of qualitative data

\begin{tabular}{|c|c|}
\hline Themes & Categories \\
\hline \multirow{3}{*}{ Meaning of bullying } & Definition of bullying \\
\hline & Setting and sources of bullying \\
\hline & Forms and incidence of bullying \\
\hline \multirow{3}{*}{$\begin{array}{l}\text { Factors contributing } \\
\text { to bullying }\end{array}$} & Stress \\
\hline & Inconsistency in communication \\
\hline & Cultural safety \\
\hline \multirow{3}{*}{ Impact of bullying } & Anxious going for clinical practice \\
\hline & Anxious about not completing program \\
\hline & Reduced confidence and self-esteem \\
\hline \multirow{3}{*}{$\begin{array}{l}\text { Coping with } \\
\text { bullying }\end{array}$} & Preparing for clinical practice \\
\hline & Desiring to be a nurse \\
\hline & Finding supporting systems \\
\hline \multirow{4}{*}{$\begin{array}{l}\text { Preventing bullying } \\
\text { behaviours }\end{array}$} & Training \\
\hline & Creating comfortable learning environment \\
\hline & Communication \\
\hline & Advocacy \\
\hline
\end{tabular}

\subsubsection{Integrating data in mixed method design}

An important component of a mixed methods approach is to combine data from both quantitative and qualitative phases to enhance deeper understanding of the research topic and integrate data. ${ }^{[22]}$ The five themes that emerged from the qualitative data provided in-depth explanations about participants' experiences of bullying during clinical practice and will be highlighted in the discussion section. 


\section{Discussion}

Globally, bullying is a major concern in the nursing profession. ${ }^{[2-5,13]}$ Although the findings from this study showed that only four $(7.7 \%)$ of the participants from the survey frequently experienced bullying during clinical practice, more than $60 \%$ of students reported that the behaviour had occurred occasionally, which aligns with the report in the literature that nursing students felt discriminated against during clinical placement and makes the topic an important one to address. ${ }^{[2]}$ Bullying may occur as a repeated behaviour or a single act and can be confirmed from the negative effects on the victim. This finding on the meaning of bullying is consistent with what has been reported in the literature. ${ }^{[1,2,4,8]}$

Students indicated in both the survey and individual interviews that the clinical setting was the place bullying occurred most and reported that clinical instructors and nurses on the floor, including registered nurses and licensed practical nurses, were the main sources of bullying. The findings on the setting and sources of uncivil behaviour to nursing students when in the clinical setting are similar to those reported in the literature. ${ }^{[1,2,4,8]}$

The most common forms of bullying attitudes that students shared in both the quantitative and qualitative data were social exclusion involving behaviours such as ignoring students, not taking their ideas into consideration, undervaluing or belittling them, and not responding to students when they asked for help. Social exclusion behaviours are salient; sometimes students are uncertain if they are being bullied, and therefore, these behaviours are underreported as seen in this study and affirmed in the literature. ${ }^{[1,2,6,9]}$ In this study, verbal harassment was the second most frequent type of bullying, which aligns with findings reported in the literature. However, physical harassment was the least reported form of bullying in this study, which was a different result from previous research findings about physical harassment, including hitting, that nursing students experienced in clinical settings.

A unique finding from this research is the high level of stress among clinical nurses, which students attributed to be the main cause of incivility among clinical nurses. Participants shared that the nurses had high levels of stress because the units were understaffed, and as a result, many nurses were working overtime. The increased level of stress in nursing as a result of nurses' high workload, contributing to incivility among nurses, is reported in the literature. ${ }^{[10,20]}$ Similarly, participants highlighted incongruent communication between clinical instructors and clinical nurses on expectations of students as a contributing factor to students being bullied on the floor. Furthermore, cultural safety was identified as another cause of bullying in the clinical setting and a

Published by Sciedu Press possible reason for the low response rate in the study. While there are not many minority students such as Black and Indigenous students in the program which is reflected in the study's demographic data, four out of the six participants in the qualitative component of the study were Blacks; these four students attributed part of the negative behaviours they experienced in the clinical setting to their racial background. Authors on cultural competency have recommended that nursing programs should provide training on cultural safety to faculty members, clinical instructors, and nurses in the clinical setting in order to enable them work effectively with students as well as retain students from minority background in the program. ${ }^{[29-32]}$

Psychological effects of bullying such as low self-esteem, impaired learning, anxiety, loss of concentration, decreased motivation, crying, embarrassment, humiliation, loss of confidence, and feelings of powerlessness were the major impacts on students and are similar to previous studies' findings. ${ }^{[1,2,4,6,33]}$ The students especially had anxiety about failing the clinical course, which generated different responses from them such as being angry, defensive, withdrawn, and scared to ask questions. The students also discussed the physical effects of bullying including stress, gastrointestinal disturbance, fatigue, and sleep disturbance. In other research, students have called in sick, and some permanently decided to leave the nursing program. ${ }^{[1,9]}$ Part of the reason students remained in the nursing program being studied was their desire to become a registered nurse, as they explained in the qualitative data. The other reason for students remaining in the program was likely due to the low incidence of incivility in the program, contrary to most studies which had more than $40 \%$ of their students experienced bullying in clinical practice. ${ }^{[1-4]}$

The findings from this study showed that the students' initial source of support in copying with bullying was their peers. This finding confirms previous studies' reports and the importance of strengthening peer support in nursing programs ${ }^{[6]}$ A concerning trend from the data is that half of the participants did not know about the process of reporting bullying incidents and whether there was a support system in the program for them. This finding is contrary to other studies in which more than $50 \%$ of the students were aware of where to report such incidents. ${ }^{[2,4]}$ Some students in the current study shared how their clinical instructors advocated for them when the person bullying them was a clinical nurse. Researchers on the topic have discussed that policy on bullying must be made clear and available to students and must assure them that the faculty will address negative behaviours during clinical practice. ${ }^{[2,4]}$ 
This research is the first study within this particular western Canadian province to examine the nature of bullying in the undergraduate nursing program during students' clinical practice. Although the majority of the students did not frequently experience bullying, the small number who encountered the behaviour reported similar characteristics and effects of bullying, which makes the topic an important one for the nursing discipline to address because of its implications on the profession and workforce in the health care system.

\subsection{Implications and recommendations}

Bullying behaviours have negative impacts on students such as poor academic performance, sleep disturbance, anxiety, poor concentration, and many implications for the health care system including patients' safety. Based on the findings from this study, the researchers recommend that academic and health care institutions involved in the preparation of nursing students must work together on the following:

1) Policies must be developed that communicate behaviours that are considered uncivil and the consequences of such attitudes on perpetrators in order to create a safe learning environment for students.

2) Students must be made aware of the policy and the office or person to report bullying attitudes to, encouraged to speak up against negative behaviours, and reassured they will not be penalized for reporting a valid incident.

3) Clinicians must be given training on bullying and made aware that the behaviour is not tolerated in the profession.

4) Wards accepting students need to assess staff workload and reduce overtime on the floor.

5) Nursing faculties must identify a contact person who could be the student advisor and come between students and their perpetrators when there is a concerning behaviour in the clinical setting.

\subsection{Limitations}

The main limitation of this study was the small sample size and low response rate. Data from the study were taken from one nursing program in the province, and as a result, the sample size was small and may not represent all nursing students in the province. The researchers suggest a larger sample size involving all nursing programs in the province in order to be able to generalize the findings. The low response rate is another limitation of the study which may be associated with cultural safety where minority students felt unsafe to report or participate in a study on bullying. The title of the research is another limitation of the study which may have contributed to the low response rate and prevented some students from participating because they were afraid to report their experiences. The researchers observed during the data collection that some students declined to participate in the interview after putting their names forward to be part of the study. The researchers are of the opinion that the students declined to participate in the study because they were afraid of being victimized even though students had been assured of anonymity and confidentiality in the study. Future research may consider using different words such as "unpleasant experience" instead of "bullying" when recruiting students to their study.

\section{Conclusion}

The findings from this study show that a small number of the students from the nursing program involved in the study frequently experienced negative behaviours in the clinical setting. Of the small number of students who reported being bullied, the effects of the behaviour on them are similar to what has been reported in the literature. Some other unique findings from this research are that clinical nurses experienced high levels of stress due to being understaffed on the floor, and the majority of the students did not know who to contact as well as did not feel supported in addressing bullying behaviour. However, the students were willing to remain in the nursing program because of their desire to become registered nurses in the future. Based on these findings, the researchers have made recommendations for policy development such as reporting bullying behaviours and training nurses to address bullying of nursing students during clinical practice in order to create a safe learning environment and to attract and retain young people in the profession.

\section{ACKNOWLEDGEMENTS}

The researchers would like to express their sincere gratitude to the Presidents' Teaching and Learning Scholar's Program committee for awarding the funding for this study. Our appreciation goes to the office of the Dean of Nursing for supporting the project and the students for sharing their experiences. We would also like to thank Amanda Matebekwane for assisting with the data analysis.

\section{Conflicts of InTERest Disclosure}

The authors have no competing conflict of interest.

\section{REFERENCES}

[1] Birks M, Budden ML, Bierdermann N, et al. A 'rite of passage?' Bullying experiences of nursing students in Australia. Collegian. 2018;
25: 45-50. https://doi.org/10.1016/j.colegn.2017.03.0 05

[2] Budden ML, Birks M, Bagley T, et al. Australian nursing students' 
experience of bullying and/or harassment during clinical placement. Collegian. 2017; 24: 125-133. https://doi.org/10.1016/j.co legn.2015.11.004

[3] Clarke CM, Kane DJ, Rajacich DL, et al. Bullying in undergraduate nursing education. Journal of Nursing Education. 2012; 51(5): 269276. PMid:22495922 https://doi.org/10.3928/01484834-2 0120409-01

[4] Tee S, Ozcetin Y SO, Russell-Westhead M. Workplace violence experienced by nursing students: a U. K. Survey. Nurse Education Today. 2016; 41(7): 30-35. PMid:27138479 https://doi.org/10.101 $6 / j$. nedt. 2016.03 .014

[5] Hutchinson M, Jacjson D, Haigh C, et al. Editorial: five years of scholarship on violence, bullying, and aggression towards nurses in the workplace: What have we learned? Journal of Clinical Nursing. 2013; 22 (7-8): 903-905. PMid:23480497 https://doi.org/10 $.1111 /$ jocn. 12139

[6] Courtney-Pratt H, Pich J, Levett-Jones T, et al. "I was yelled at, intimidated and treated unfairly": nursing students' experiences of being bullied in clinical and academic settings. Journal of Clinical Nursing. 2018; 27: e903-e912. PMid:28771876 https ://doi .org/10.111 $1 /$ jocn. 13983

[7] Gillespie GL, Grubb PL, Brown K, et al. Nurses eat their young: a novel bully educational program for student nurses. Journal of Nursing Education and Practice. 2017; 7(7): 11-21. PMid:28781715 https://doi.org/10.5430/jnep.v7n7P11

[8] Salin D. Ways of explaining workplace bullying: a review of enabling, motivating and precipitating structures and processes in the work environment. Human Relations. 2003; 56(10): 1213-1232. https://doi.org/10.1177/00187267035610003

[9] Cooper J, Walker J, Askew R, et al. Students' perceptions of bullying behaviours by nursing faculty. Issues in Educational Research. 2011; 21(1): 1-15.

[10] Baltimore JJ. Nurse collegiality: fact or fiction. Nursing Management. 2006; 37(5): 28-36. PMid:16651900 https://doi.org/10.109 7/00006247-200605000-00008

[11] Aul K. Who's uncivil to who? Preceptions of incivility in prelicensure nursing programs. Nurse Education in Practice. 2017; 27: 36-44. PMid:28843175 https://doi.org/10.1016/j.nepr.2 017.08 .016

[12] Lupare S. Incivility in nursing: the connection between academia and clinical settings. Critical Care Nurse. 2011; 31(2): 92-95. PMid:21459868 https://doi.org/10.4037/ccn2011171

[13] Magnativa N, Heponiemi T. Workplace violence against nursing students and nurses: an Italian experience. Journal of Nursing Scholarship. 2011; 43(2): 203-210. PMid:21605325 https://doi.org/ $10.1111 / j .1547-5069.2011 .01392 . x$

[14] Small SP, English D, Moran G, et al. Mutual respect would be a good starting point: Students' perspectives on incivility in nursing education. Canadian Journal of Nursing Research. 2018; 51(3): 133-144. PMid:30596286 https://doi.org/10.1177/08445621188215 73

[15] Anderson C, Moxham L, Broadbent M. Teaching and supporting nursing students on clinical placements: doing the right thing. Collegian. 2018; 25(2): 231-235. https ://doi.org/10.1016/j.cole gn. 2017.06.005

[16] The Canadian Higher Education Data Base. Becoming a registered nurse. 2012. Available from: http://www.degrees.ca/registe red-nurse/

[17] Borrott N, Day GE, Sedwick M, et al. Nursing students' belonginess and workplace satisfaction: Quantitative findings of a mixed methods study. Nurse Education Today. 2016; 45: 39-34. PMid:27429400 https://doi.org/10.1016/j.nedt.2016.06.005

[18] Qutishat M. Underreporting bullying and harassment perceived by undergraduate nursing students: A descriptive study. International Journal of Mental Health and Psychiatry. 2019; 5(1).

[19] Siebel M. For us or against us? Perceptions of faculty bullying of nursing students during undergraduate nursing education clinical experience. Nurse education in Practice. 2014; 14: 271-274. PMid:24090522 https://doi.org/10.1016/j.nepr.2013.08 .013

[20] Smith CR, Brown KC, Grubb PL. Seeing students squirm: nursing students' experiences of bullying behaviors during clinical rotations. Journal of Nursing Education. 2016; 55(9): 505-513. PMid:27560118 https://doi .org/10.3928/01484834-20160816-04

[21] Creswell JW. Research design: Qualitative and quantitative \& mixed methods approaches (4rd Ed.). Thousand Oaks: Sage Publications; 2014.

[22] Creswell JW, Plano CVL. Designing and conducting mixed methods research. Los Angeles: SAGE Publications; 2011.

[23] University of Regina, Saskatchewan Polytechnic. Saskatchewan collaborative programs in nursing [Internet]. 2019 [cited 2019 Nov7]. Available from: https://www.sasknursingdegree.ca/scbsc n/year-1/

[24] Braun V, Clarke V. Thematic analysis. In H Cooper, P M Camic, D L Long, A T Panter, D Rindskopf, K J Sher (Eds), APA handbook of research methods in psychology, Vol. 2: Research designs: Quantitative, qualitative, neuropsychological, and biological Washington, DC: American Psychological Association; 2012. 57-71p.

[25] Clarke V, Braun V. Teaching thematic analysis: over-coming challenges and developing strategies for effective learning. The Psychologist. 2013; 26(2): 120-123.

[26] Lincoln YS, Guba EG. Naturalistic Inquiry. Beverly Hills, CA: Sage Publications, Inc.; 1985.

[27] Puplampu V, Ross C. Nursing faculty and student transition to a context-based learning curriculum. Journal of Nursing Education and Practice. 2017; 7(7): 54-65. https://doi.org/10.5430/jnep.v $7 \mathrm{n} 7 \mathrm{p} 54$

[28] Gregory D, Raymond-Seniuk C, Patrick L, et al. Fundamentals: perspectives on the art and science of Canadian nursing. Philadelphia (PA): Wolters Kluwer/Lippincott Williams \& Wilkins; 2015.

[29] Bednarz H, Schim S, Doorenbos A. Cultural diversity in nursing education: perils, pitfalls, and pearls. Journal of Nursing Education. 2010; 49(5): 253-260. PMid:20143759 https://doi.org/10.3 928/01484834-20100115-02

[30] Diaz C, Clarke PN, Gatua MW. Cultural competence in rural nursing education: are we there yet? Nursing Education Perspectives. 2015; 36(1): 22-26. PMid:29194152 https://doi .org/10.5480/12-1 066.1

[31] Sedgwickm M, Oosterbroek T, Ponomar P. "It all depends": how minority nursing students experience belonging during clinical experiences. Nursing Education Perspectives. 2014; 35(2): 88-93. PMid:24783723 https://doi .org/10.5480/11-707.1

[32] Ume-Nwagbo P. Implications of nursing faculties' cultural competence. Journal of Nursing Education. 2012; 51(5): 262-268. PMid:22432533 https://doi .org/10.3928/01484834-20120 323-01

[33] Laschinger HKS, Nosko A. Exposure to workplace bullying and posttraumatic stress disorder symptomology: the role of protective psychological resources. Journal of Nursing Management. 2015; 23: 252262. PMid:24033807 https://doi.org/10.1111/jonm. 12122 